\title{
The impact of potted street gardens on depression levels in a dense residential neighborhood: case of Beni-Makada, Tangier
}

\author{
${ }^{1}$ Afrad Abdellah ${ }^{\text {a* }},{ }^{\text {b }}$ Yoshiyuki Kawazoeb \\ ${ }^{\mathrm{a}, \mathrm{b}}$ Tokyo University, Meguro-ku, Komaba 4-6-1, S202. 153-8505, Tokyo, Japan
}

\section{Abstract}

\section{Purpose of the Study}

We aimed to investigate the interactive effects of street potted gardens ownership with depression levels.

\section{Design and Methods}

This study included 388 participants from a face-to-face survey we conducted in January 2019, in Tangier, Morocco. Hypotheses were tested using weighted hierarchical ordinary least squared regression analysis.

\section{Results}

Street potted gardens ownership and Neighborhood life quality satisfaction were significantly associated with depression score, high neighborhood satisfaction levels were associated with low depression scores, while SPGs ownership was associated with higher depression levels. SPGs ownership buffered the negative association between depression levels and neighborhood satisfaction.

\section{Implications}

Findings suggest that SPGs ownership is related to high levels of depression, an unexpected result that suggest more research be done about the interactions between SPGs ownership and health in general.

\section{Introduction}

Street potted gardens (SPGs) are the green space of deprived communities, they are sometimes the only form of urban green they can interact with, especially in dense neighborhoods. Yet the possible effects of this interaction are extremely understudied. Most of the research about SPGHuman interactions was done in Japan in relation with territoriality and community life. Their presence was positively associated with neighborhood greenery perception and negatively associated with green space availability, which shows its great potential as a tool to reduce green space shortage in urban environments, especially in dense disadvantaged neighborhoods. But To our knowledge no study verified if SPGs do have the same positive impact, conventional forms of green space have on mental health. In this paper we focused on the relationship between SPGs

\footnotetext{
${ }^{1}$ Corresponding Author: afrad@iis.u-tokyo.ac.jp
} 
ownership and depression, in a dense low-income residential neighborhood in the city of Tangier, Morocco, using a face-to-face survey $(N=388)$ conducted in January 2019.

An impressive body of literature studied and confirmed the positive impact urban green spaces have on mental health, such as reducing depression and stress levels (Ulrich et al., 1991; Koga \& Iwasaki, 2013; Jiang, Li, Larsen, \& Sullivan, 2016; Bratman, Hamilton, Hahn, Daily, \& Gross, 2015; Kotozaki, 2013), increasing neighborhood safety perception, (Garvin, Cannuscio, \& Branas, 2012; Gorham, Waliczek, Snelgrove \& Zajicek, 2009), neighborhood satisfaction (Zhang, Van den Berg, Van Dijk \& Weitkamp. 2017), and social cohesion (Jennings \& Bamkole; 2019).

Some studies also found that the amount of urban green space was positively associated with mental health, and that this association was stronger among disadvantaged ethnic minorities and lower socioeconomic status communities, in addition to those that spend more time at home, including the elderly (Maas, Verheij, Groenewegen, De Vries \& Spreeuwenberg, 2006; Waliczek, Mattson \& Zajicek, 1996).

These findings suggest that increasing the quantity of urban green space in residential neighborhoods would significantly improve mental health, especially for socioeconomically disadvantaged communities. However, green space is still not equitably distributed through urban environments in terms of quantity, quality and proximity (Wolch, Byrne \& Newell, 2014), especially in developing countries where planning urban green space is viewed as an expensive luxury by local governments (Cilliers \& Timmermans, 2012).

Consequently, one of the most interesting solutions for this shortage in dense residential neighborhoods didn't come from government initiatives but from the spontaneous ingenuity of locals, that decorate their front houses with Potted Gardens. Some studies in Japan found that these Street Potted Gardens (SPGs) were associated with an increase in neighborhood greenery perception and negatively associated with green space availability (青木義次\&湯浅義晴， 1993), which effectively suggests that SPGs may be a suitable solution to urban green space shortage in dense residential neighborhoods.

SPGs were studied mainly in the Japanese context, as typical component of Japanese alleys and residential neighborhoods in general. Research showed its beneficial effects on local communities, its role in organizing community space (Masuda, Sadahiro, Hino \& Usui, 2018. Takahashi, Itoh \& Shimomura, 2005. 青木義次＆湯浅義晴, 1993; Ikkai, Shimizu, Sato \& Chen, 1999) and in increasing perceived neighborhood greenery (水上象吾 \& 萩原清子，2001). But to our knowledge no research studied or quantified its impact on mental health, despite the existence of consistent research on the effect of conventional urban green space and horticulture on depression and stress (Martinsen, 2009). This could be because Street Potted Gardens are not recognized as a form of green space, since their maintenance and existence, depends entirely on their owners, and are generally smaller, privately owned and, more often than not "illegally " occupying public space, like sidewalks or roads reserved for car traffic (Jonas, 2011).

Therefore, this research 'objective is to study the relationship between street potted gardens ownership and three aspects of neighborhood life, that were found to have a direct impact on depression levels; namely, perceived neighborhood safety, where safer neighborhoods were associated with lower depression levels (Gonyea, Curley, Melekis \& Lee, 2018), neighborhood satisfaction, where high levels of neighborhood characteristics satisfaction were associated with 
low levels of depression (Julien, Richard, Gauvin \& Kestens, 2012), and social capital where higher levels of social cohesion were associated with lower levels of depression (Lee, Lee \& Song, 2019). We extend prior research on urban green space associations with depression among disadvantaged communities to explore: (a) if SPGs ownership is associated with depression levels and (b) whether SPGs ownership is moderating the potential relationship between neighborhood safety, neighborhood satisfaction and social capital in one side and depression levels on the other side. In line with our literature review we advance the following hypotheses:

Hypothesis 1: SPGs ownership, neighborhood safety, satisfaction and social capital and will be negatively associated with depression levels.

Hypothesis 2: SPGs ownership will be moderating the association between depression and neighborhood safety, satisfaction and social capital.

Such studies are very important for the development of effective strategies to reduce depression's negative impact on mental health and well-being, that is today, the leading cause of disability in the world according to the world health organization (WHO, 2017).

\section{Methodology}

\section{Data}

The data used is derived from a face-to-face survey $(\mathrm{N}=388)$ we conducted in January 2019 , in the Beni-Makada district of Tangier, one of the most disadvantaged neighborhoods (World Bank. 2012) with a per capita green space of $0.27 \mathrm{~m}^{2}$ the smallest in the city (OPEMH, Friedrich-Ebert-Stiftung foundation, 2016).

The district is famous for the abundance of street potted gardens, widely mediatized during the $22^{\text {and }}$ conference of parties (COP22) organized in 2016 in Morocco. It houses more than $40 \%$ of Tangier's population, mostly middle-low to low-income, living in individual houses (Modern Moroccan houses), built directly to the property line, $65 \%$ of urban families in Morocco live in the same housing type (RGPH 2014). All SPGs observed in the study area were present in the public domain, the great majority were back to back with owners' houses, except for two narrow streets where SPGs were placed at the center to barre access to cars.

The questionnaire was tested and verified with focus groups in Arabic, before being conducted in Morocco. The final version was composed of 4 parts and 36 questions. The first part was made of SPGs related questions about their size, age and activities related to its maintenance like watering and cleaning, in addition to recreational activities done next to it, like eating, sitting, chatting, etc. Part 2 was composed of 18 questions about neighborhood satisfaction, cleanliness, safety, noise annoyance and social relations between neighbors, in addition to neighborhood life quality and belonging pride perception. Part 3 was composed of the Arabic version of the Patient Health Questionnaire (PHQ-9), used to assess the severity of depression. Part 4 was composed of demographic questions.

Four trained interviewers conducted face-to-face interviews with the participants. The questionnaires were either filled by the interviewers (in the case of illiterate respondents), or by the participants themselves in their homes, work places or on the streets. During every face-to-face interview every potential participant receives extensive information about the survey, its aims, the length and content of the questionnaire, and the confidentiality. Anonymity and exclusive use of the collected data for scientific research objectives are explained in detail. Participants were then 
asked to fill the questionnaire, about $80 \%$ accepted to participate in the survey. After 4 weeks 389 questionnaires were collected, a total of 388 surveys were valid, one copy was returned with only 3 questions answered.

\section{Measures}

Depression assessment. Depression score was measured using the Arabic version of the Patient Health Questionnaire (PHQ-9). The PHQ-9 is a nine-item tool assessing depression severity with user-friendly response format. Respondents were asked to rate the frequency of 9 symptoms over the past 2 weeks. Response options are (0) "not at all ", (1) "several days", (2) "more than half the days, "and (3) "nearly every day". Items were summed to create a score where higher values indicate more severe depression. The summed score ranged from 0 to 27 . The internal consistency of the items was satisfactory (Cronbach's $\alpha=.73$ ).

The PHQ-9 has also a final question at the end of the diagnostic portion of the PHQ-9, asking patients who checked off any problems on the questionnaire: "How difficult have these problems made it for you to do your work, take care of things at home, or get along with other people?." with responses (1) "Not difficult at all," (2) "Somewhat difficult," (3) "Very difficult," and (4) "Extremely difficult." But we did not use this question during the data analysis.

Perceived neighborhood life quality satisfaction was measured using a satisfaction index summing participant's answers to two questions: "How satisfied or dissatisfied are you with the life quality in your neighborhood" with responses (1) "not satisfied at all," (2) "not satisfied," (3) "average," (4) "satisfied ," and "very satisfied". And "how proud are you to live in this neighborhood" with responses (1) "not proud at all," (2) "not proud," (3) "average," (4) "proud," and "very proud". The summed score ranged from 0 to 10 . The internal consistency of the items was good (Cronbach's $\alpha$ $=.881)$.

Perceived neighborhood social capital was measured using a social capital index summing participants answers to two questions "How would you describe the relationship between neighbors in your neighborhood" with responses (1) "very bad," (2) "bad," (3) "neutral," (4) "good," and "very good". And "how many of your neighbors do you know" with responses (1) "none of them," (2) "few of them," (3) "half of them," (4) "most of them," and "all of them". The summed score ranged from 0 to 10 . The internal consistency of the items was good (Cronbach's $\alpha$ $=.786)$.

Perceived neighborhood safety was measured using the question: "how safe is your neighborhood?" with responses (1) "very unsafe," (2) "unsafe," (3) "neutral," (4) "safe," and "very safe".

SPGs age was measured in months using the question "Since when there are potted plants in front of your house".

SPGs size was measured in months using the question "How many pots are in your garden", measuring, in number of plant pots.

Time spent caring for SPGs every week was measured in minutes by multiplying the numerical answers to two questions "How many times a week do you take care of these plants" with responses ranging from (0) "Never" to "7 times a week", and "How much time do you spend taking care of your garden daily" measuring Daily care time in minutes.

Diversity of recreational activities done next to SPGs was assessed using the question "What kind of activities do you do next to your pots" a check-All-That-Apply question, with responses, (0) "nothing", (1) "sitting or standing", (1) "eating", (1) "chatting", (1) "smoking", and (1) "other". 
Weekly frequency of recreational activities done next to SPGs was measured using the question "On average, how many times a week do you have activities in or next to your pots", with responses ranging from (0) "Never" to "7 times a week"

And SPGs publicness was measured using the question "Do you think that your potted garden is" with responses (1) "private", (2) "both", and (3) "Public".

Demographic covariates included are age category, gender, household size, House ownership (yes/no), car ownership(yes/no), marital status (single/ married / widowed / divorced), occupation (student/Self-employed/ employee/ Retired/ Housewife/ Unemployed/other), educational level, (Less than high school /vocational training/ high school/ bachelor/Masters/PhD/ other), duration of residence (time lived at current address in years), and walking distance to closest garden (in minutes)

\section{Analysis Plan}

To compare the variance in depression levels between participants with and without SPGs, we conducted Bivariate analyses to show the association patterns among our key variables. We then conducted weighted hierarchical ordinary least squared (OLS) regression analysis (white's test of heteroscedasticity was significant $F=4.417 ; p<.05$ ) using SPSS 25 , to examine the effects of SPGs ownership, neighborhood safety, neighborhood life quality satisfaction and neighborhood social cohesion on depression score, measured with the PHQ-9, controlling for demographic variables. First in model 1 we tested the relationship between Depression score and our independent variables. Next in Model 2 we added the interaction terms between SPGs ownership and each neighborhood perceived safety, neighborhood life quality satisfaction and neighborhood social capital.

Finally we conducted a second OLS for the SPGs owners group only adding the independent variable related to SPGs ownership; SPGs age, size, weekly care time, publicness, diversity of activities done next to SPGs and its frequency.

\section{Results}

\section{Descriptive Statistics}

As can be seen in Table 1, the average depression score is $1.38(S D=2.22)$ on a scale of $0-25$, which indicates an overall minimal depression (Kroenke, Spitzer \& Williams, 2001), 7.1\% of our sample had mild depression while only $1.4 \%$ had moderate depression, lower than the rate in the general population in Morocco which is $26.5 \%$ (Moussaoui, 2007).

Over two thirds of the sample (68\%) reported having a Street Potted Garden in front of their houses. While $82 \%$ of participants perceived their neighborhoods as being "safe" or "very safe", The average neighborhood life quality satisfaction score was 8.04 (range $0-10 ; S D=1.14$ ).

The majority of the sample was Men (69.8\%), owned their houses (56.1\%). The average age was $2.54(S D=0.82$ ) which is between 18 and 35 years old, the average level of education was 2.68 (range 0-6; $S D=1.68$ ), or between vocational training and high school graduate, the average household size was $4.92(S D=1.70)$ and the average duration that participants lived at their current address was 23 years $(S D=10.83)$.

Table 1. Descriptive Information on the Analytic Sample ( $N=388)$ 


\begin{tabular}{|c|c|c|c|}
\hline Response & Whole sample & No SPGs & With SPGs \\
\hline \multicolumn{4}{|l|}{ SPGs ownership } \\
\hline Yes & $68 \%$ & & \\
\hline No & $32 \%$ & & \\
\hline PHQ-9 score & $\mathrm{M}=1.38 ; \mathrm{SD}=2.221$ & $M=0.76 ; S D=1.38$ & $M=1.68 ; S D=2.47$ \\
\hline $\begin{array}{l}\text { Neighborhood Safety } \\
\text { perception }\end{array}$ & $3.91(0.771)$ & $3.90(0.712)$ & $3.91(0.798)$ \\
\hline Not safe at all & 2 & $0.8 \%$ & $0.4 \%$ \\
\hline Not safe & 27 & $6.6 \%$ & $7.2 \%$ \\
\hline Neutral & 40 & $5.8 \%$ & $12.5 \%$ \\
\hline Safe & 250 & $75.2 \%$ & $60.5 \%$ \\
\hline Very safe & 65 & $11.6 \%$ & $19.4 \%$ \\
\hline $\begin{array}{l}\text { Neighborhood life } \\
\text { quality satisfaction } \\
\text { (range } 0-10 \text { ) }\end{array}$ & $M=8.04 ; S D=1.14$ & $M=7.7 ; S D=1.08$ & $M=8.20 ; S D=1.13$ \\
\hline $\begin{array}{l}\text { Neighborhood social } \\
\text { capital }\end{array}$ & $\mathrm{M}=7.98 ; \mathrm{SD}=1.41$ & $\mathrm{M}=7.91 ; \mathrm{SD}=1.67$ & $\mathrm{M}=8.01 ; \mathrm{SD}=1.26$ \\
\hline \multicolumn{4}{|l|}{ Gender } \\
\hline Male & $271(69.8 \%)$ & $92(74.2 \%)$ & $179(67.8 \%)$ \\
\hline Female & $117(30.2 \%)$ & $32(25.8 \%)$ & $85(32.2 \%)$ \\
\hline Age category (range 1-5) & $M=2.54 ; S D=0.82$ & $\mathrm{M}=2.48 ; \mathrm{SD}=0.78$ & $\mathrm{M}=2.57 ; \mathrm{SD}=0.84$ \\
\hline Education & $M=2.68 ; S D=1.68$ & $\mathrm{M}=2.74 ; \mathrm{SD}=1.68$ & $M=2.66 ; S D=1.69$ \\
\hline \multicolumn{4}{|l|}{ Marital status } \\
\hline Single & $49.7 \%$ & $52.4 \%$ & $47.7 \%$ \\
\hline Married & $40.6 \%$ & $38.2 \%$ & $41.3 \%$ \\
\hline Widowed & $4.9 \%$ & $4.9 \%$ & $4.9 \%$ \\
\hline Divorced & $2.3 \%$ & $3.3 \%$ & $1.9 \%$ \\
\hline \multicolumn{4}{|l|}{ House ownership } \\
\hline Yes & $56.1 \%$ & $56.5 \%$ & $55.7 \%$ \\
\hline no & $43.9 \%$ & $42.7 \%$ & $44.3 \%$ \\
\hline $\begin{array}{l}\text { Years living in the } \\
\text { neighborhood }\end{array}$ & $M=23 ; S D=10.83$ & $M=23.75 ; S D=11.45$ & $M=23.25 ; S D=10.55$ \\
\hline House hold size & $M=4.92 ; S D=1.70$ & $M=4.86 ; S D=1.79$ & $\mathrm{M}=4.95 ; \mathrm{SD}=1.64$ \\
\hline
\end{tabular}

Boldface indicates $p<.05$ for SPGs owners compared to those with no SPGs.

Bivariate Analysis

We performed bivariate analyses ( $t$ tests and chi-square tests) to identify significant differences in characteristics between participants with SPGs and those without SPGs (see Table 1).

Respondents with SPGs, had significantly higher depression scores and were less likely to perceive their neighborhoods as being safe, but were more likely to perceived high levels of neighborhood life quality satisfaction than those without SPGs. 
Overall there were no significant differences between the participants with and without SPGs in terms of neighborhood social capital, gender, age category, education, marital status, house ownership, years lived in current address or household size.

Pearson's correlations were also calculated among our four key variables, depression score, neighborhood safety, neighborhood satisfaction and social capital, for respondents with and without SPGs. Results showed that for participants without SPGs, depression score was significantly correlated only with neighborhood satisfaction $(r=-.333 ; p<.001)$ and social capital $(r=$ -.209; $p<.05$ ), there were no significant associations between perceived neighborhood safety and other variables, while neighborhood satisfaction and social capital were significantly associated $(p<.001)$. For those with SPGs, depression score was not significantly associated with any other variable. Life quality satisfaction, social capital and neighborhood safety were all positively associated with each other $(p<.001)$.

\section{Multivariate Analysis 1}

Table 2 shows the results of the Weighted Least Squares regression predicting depression score, stratified by weather or not participants had SPGs in front of their houses or not.

As can be seen in model1, among respondents owning an SPGs, neighborhood life quality satisfaction ( $b=.013, C l=-.243 / .270 . p=.920)$, Social Capital $(b=.055, C l=-.178 / .289 . p=.641)$ and neighborhood safety $(b=.080, C l=-.237 / .398 . p=.619)$ did not have a significant association with depression score. Among participants that didn't have an SPG in front of their houses, an increase of 1 point in Neighborhood life quality satisfaction index was associated with a 0.714 point decrease in depression score.

Table 2. Weighted hierarchical Least square regression explaining depression score $(\mathrm{N}=388)$

\begin{tabular}{|c|c|c|c|c|}
\hline & Model 1 & & Model 2 & \\
\hline & With SPGs & No SPGs & Step 1 & Step 2 \\
\hline & $b(C I)$ & $b(C I)$ & $b(C I)$ & $b(C I)$ \\
\hline SPGs ownership yes & - & - & $.745^{* * *}(.38 / 1.10)$ & $.780 * * *(.41 / 1.14)$ \\
\hline $\begin{array}{l}\text { Neighborhood life } \\
\text { quality satisfaction }\end{array}$ & $.013(-.243 / .270)$ & $\begin{array}{l}-.714 * * * \\
(-1.046 /-.382)\end{array}$ & $-.307^{* *}(-.50 /-.11)$ & $-.229 *(-.43 /-.03)$ \\
\hline $\begin{array}{l}\text { Neighborhood Safety } \\
\text { perception }\end{array}$ & $.080(-.237 / .398)$ & $.188(-.13 / .51)$ & $.177(-.04 / .40)$ & $.088(-.15 / .33)$ \\
\hline $\begin{array}{l}\text { Neighborhood social } \\
\text { capital }\end{array}$ & $.055(-.178 / .289)$ & $-.035(-.206 / .1)$ & $-.032(-.16 / .10)$ & $.010(-.16 / .18)$ \\
\hline $\begin{array}{l}\text { Neighborhood life } \\
\text { quality satisfaction x } \\
\text { SPGs ownership }\end{array}$ & & & & $.726 * * *(.33 / 1.12)$ \\
\hline $\begin{array}{l}\text { Neighborhood social } \\
\text { capital x SPGs } \\
\text { ownership }\end{array}$ & & & & $.005(-.27 / .28)$ \\
\hline $\begin{array}{l}\text { Neighborhood Safety } \\
\text { perception x SPGs } \\
\text { ownership }\end{array}$ & & & & $-.057(-.48 / .37)$ \\
\hline Gender & & & & \\
\hline
\end{tabular}




\begin{tabular}{|c|c|c|c|c|}
\hline Female & $-.488(-1.03 / .05)$ & $-.201(-.75 / .35)$ & $-.236(-.61 / .14)$ & $-.348(-.73 / .03)$ \\
\hline $\begin{array}{l}\text { Age category } \\
\text { (range } 1-5 \text { ) }\end{array}$ & $-.136(-.59 / .32)$ & $.213(-.29 / .72)$ & $.057(-.28 / .39)$ & $.053(-.28 / .38)$ \\
\hline \multicolumn{5}{|l|}{ Marital status } \\
\hline Married & $.525(-.169 / 1.220)$ & $-.112(-.77 / .55)$ & $.028(-.443 / .50)$ & $.111(-.35 / .58)$ \\
\hline Widowed & $2.34 *(.46 / 4.23)$ & $-.021(-2.08 / 2.04)$ & $1.091(-.27 / 2.45)$ & $1.06(-.28 / 2.40)$ \\
\hline Divorced & $1.327(-.87 / 3.53)$ & $-.82(-2.43 / .78)$ & $-.090(-1.3246 / 1.144)$ & $-.157(-1.37 / 1.06)$ \\
\hline Single & - & - & - & \\
\hline Education & $.008(-.17 / .18)$ & $.067(-.109 / .243)$ & $.062(-.06 / .18)$ & $.068(-.05 / .18)$ \\
\hline House hold size & $.103(-.052 / .26)$ & $-.140(-.313 / .033)$ & $-.017(-.12 / .09)$ & $-.050(-.16 / .06)$ \\
\hline $\begin{array}{l}\text { Years living in the } \\
\text { neighborhood }\end{array}$ & $.012(-.023 / .047)$ & $-.033 *(-.06 /-.003)$ & $-.024 *(-.04 /-.002)$ & $-.019(-.040 / .003)$ \\
\hline House ownership & $.340(-.22 / .90)$ & $-.512(-1.160 / .136)$ & $-.215(-.63 / .2)$ & $-.131(-.54 / .28)$ \\
\hline Constant & -24.377 & $73.140^{*}$ & $49.031 *$ & 38.551 \\
\hline F test & 1.193 & $3.219 * *$ & $2.949 * * *$ & $3.430 * * *$ \\
\hline
\end{tabular}

b: Unstandardized Regression Coefficient

Cl: Confidence Interval

$*_{p}<.05 ; * * p<.01 ; * * p<.001$.

Model 2 show the results of the hierarchical regression; Step 1 with the main effect variables only, and Step 2 with the addition of the interaction terms.

In Step 1, SPGs owners had on average of 0.745 point higher depression scores than those without SPGs $(b=.745, C l=.38 / 1.10 ; p<.001)$, one point increase in neighborhood life quality satisfaction was associated with a 0.307 points decrease in depression score $(b=-.307, C l=-.50 /-.11 ; p<.01)$.

This result doesn't support Hypothesis 1 , that SPGs ownership is negatively associated with depression.

Step 2 tests the effects of SPGs ownership as a moderator on the relationship between depression score and neighborhood perceived safety, life quality satisfaction, and social capital. Only the interaction term between SPGs ownership and life quality satisfaction was found significant $(b=.726, C l=.32 / 1.12, p<.001)$, the additional variation explained between Step 1 and Step 2 of the analysis was $4 \%\left(F(3,336)=5.058, p<.001 . R^{2}\right.$ change $\left.=.039\right)$, which means that, in support of Hypothesis 2, SPGs ownership is a moderator to the relationship between depression score and neighborhood life quality satisfaction.

in Model 1, among respondents with SPGs, being a widow was associated with an increase of 2.34 point in depression score $(b=2.34, C l=.46 / 4.23 . p<.05)$ compared with singles, while among respondents without SPGs one year decrease in total years lived in the neighborhood was associated with a 0.033 point decrease in depression score $(b=.033, C l=-.06 /-.003 . p<.05)$, in model 2 , years lived in the neighborhood were still significant, one year increase was associated with a 0.024 decrease in depression score $(b=-.024, C l=-.04 /-.002 . p<.05)$. 


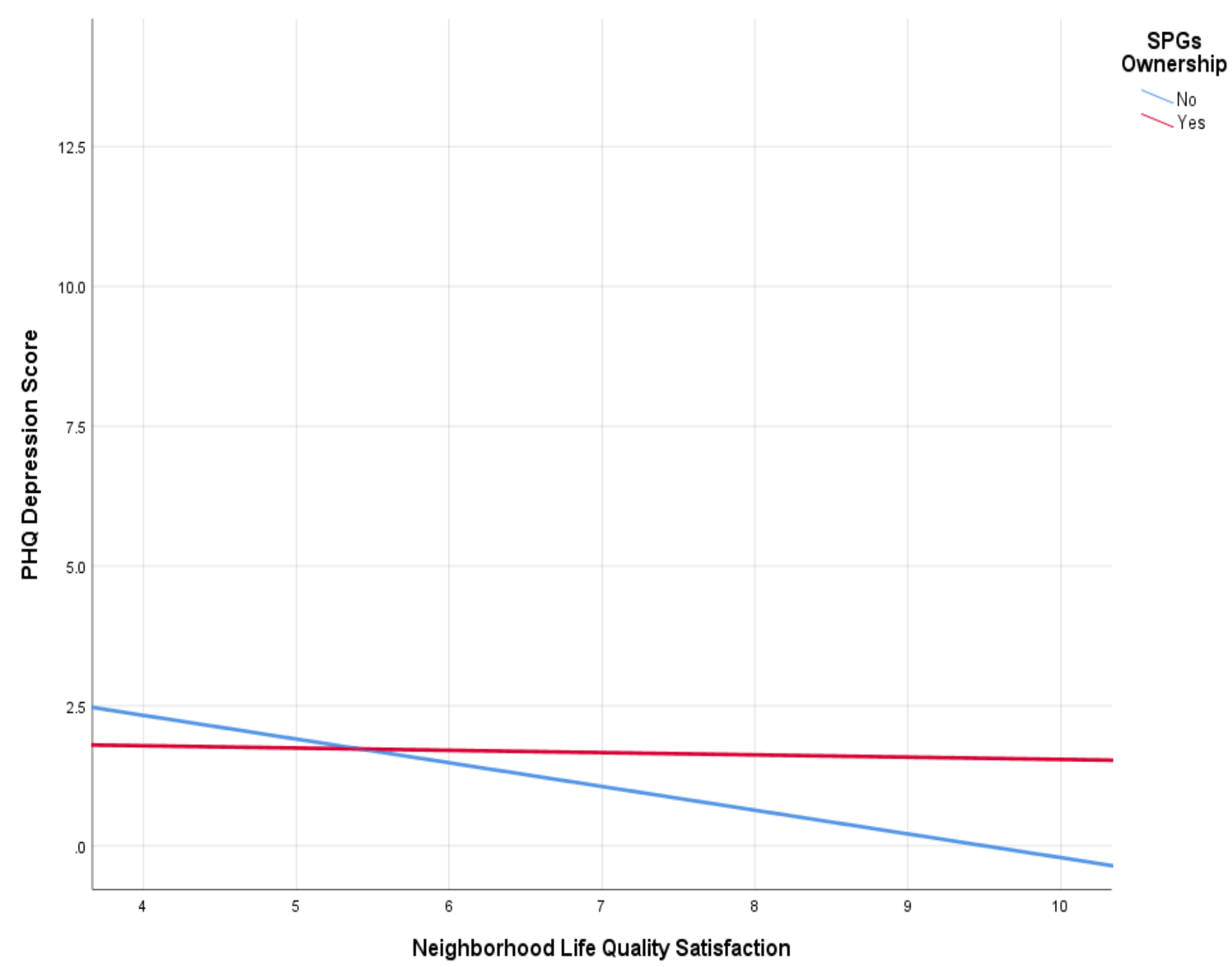

Figure 1: Simple Slopes for Income by Self-Esteem Interaction

\section{Multivariate Analysis 2}

\section{Discussion}

\section{Statement of principal findings}

Considering the great beneficial effects of urban green space on mental health, understanding the impact of its alternative forms like street potted gardens have on depression, is very important to improve life condition in dense deprived neighborhoods.

The results of this study showed that in our sample, only neighborhood satisfaction and SPGs ownership had a significant association with depression levels. In order to better understand the interactions between our variables, we studied the groups with and without SPGs separately before collapsing the whole sample into one model.

For the group of respondents with no SPGs we found that only neighborhood satisfaction had a significant association with depression, where higher satisfaction was associated with lower depression, a finding that is consistent with existing literature. Bivariate analysis showed that social capital and neighborhood satisfaction were significantly associated with each other, while perceived neighborhood safety was not correlated with any other variable. 
For SPGs owners, depression score was found to be significantly higher, compared to those with no SPGs, while neighborhood satisfaction had no association with depression levels. These results are not consistent with existing literature, that argues interaction with urban green space and gardening reduces depression (Soga, Gaston \& Yamaura, 2017). Bivariate analysis showed that social capital, neighborhood perceived safety and neighborhood satisfaction were all significantly correlated.

The results of the multivariate analysis for the whole sample indicated that SPGs ownership is negatively associated with depression but also moderates its relationship with neighborhood satisfaction. We suggest two possible explanatory hypothesis to these findings:

a) In our sample SPGs ownership cause people to have higher depression levels: all SPGs observed in our study area were located outside of respondent's houses, the Beni Makada district is one of the most disadvantaged and most unsafe neighborhoods of the city of Tangier (World Bank. 2012). Having to look after the SPGs in an uncontrolled environment may be a source of stress, low perceived control in general is known to be associated with higher depression and stress levels (Wardle et al, 2004). The fact that neighborhood safety social capital and neighborhood satisfaction were all significantly correlated with each other for SPGs owners, compared to those with no SPGs, where perceived neighborhood safety was not significantly correlated with any other variable, may be an indication that SPGs owners are more sensitive to their environment safety than those with no SPGs.

b) People with higher depression levels are more likely to have an SPG than those with low depression: Golant's (2011) theoretical model of residential normalcy may help explain this theory. The model was specifically developed in order to explain how older adults adapt to residential environment that don't fit their special needs. But it presents an interesting model that can be generalized to other underprivileged communities. The theory suggests bad residential environments can cause poor psychological well-being which triggers a process of adaptation using what he calls accommodative and assimilative strategies to achieve residential normalcy, by which they either change the way they perceive their residential environment or change its physical characteristics. SPGs can be considered an assimilative strategy caused by a poor psychological well-being, in our case depression, by which SPGs owners try to modify their neighborhoods to become more fit to their expectations.

\section{Limitations}

To our knowledge this research is the first investigation of the relationships between street potted gardens and depression. Therefore there are no similar studies with which we can compare our findings. Also the directionality of the relationship between SPGs and depression can't be verified, for example it is possible that depression causes people to have street potted gardens as much as it is possible that SPGs cause people to develop depression.

Another limitation is that the observed associations could be caused by selection bias. We tried to rule out this possibility by taking into consideration the demographic characteristics of our population, but given that our opportunities to interview females were limited ( $30 \%$ of our sample) for cultural reasons, social effects of selection cannot be ruled out completely.

Thus, further studies should explore causal relationships between SPGs ownership and mental health in general using bigger sample sizes and longitudinal data to thoroughly assess causality. 


\section{Conclusion}

Our results highlighted an unexpected association between street potted gardens and mental health in dense residential neighborhoods. SPGs ownership didn't just directly affect depression levels, but it also moderated the effect neighborhood satisfaction had on it.

These findings are very important considering the lack of research specifically about SPGs impact on health and behavior in general, and suggest that more studies be done to better understand these associations specially that SPGs are being encouraged as a cheap way to green dense neighborhoods in Morocco, assuming that it can only have a positive impact on general well-being.

\section{References}

1. Bratman, G. N., Hamilton, J. P., Hahn, K. S., Daily, G. C., \& Gross, J. J. (2015). Nature experience reduces rumination and subgenual prefrontal cortex activation. Proceedings of the national academy of sciences, 112(28), 8567-8572.

2. Cilliers, E. J., \& Timmermans, W. (2012, November). Planning for sustainable green spaces in developing countries: linking economic value to green. In IADIS International Conference on Sustainability, Technology and Education, Perth, Australia (pp. 77-84).

3. Depression and Other Common Mental Disorders: Global Health Estimates. Geneva: World Health Organization; 2017. Licence: CC BY-NC-SA 3.0 IGO.

4. Garvin, E. C., Cannuscio, C. C., \& Branas, C. C. (2012). Greening vacant lots to reduce violent crime: a randomised controlled trial. Injury prevention, injuryprev-2012.

5. Golant, S. M. (2011). The quest for residential normalcy by older adults: Relocation but one pathway. Journal of Aging Studies, 25(3), 193-205.

6. Gonyea, J. G., Curley, A., Melekis, K., \& Lee, Y. (2018). Perceptions of neighborhood safety and depressive symptoms among older minority urban subsidized housing residents: the mediating effect of sense of community belonging. Aging \& mental health, 22(12), 1564-1569.

7. Gorham, M. R., Waliczek, T. M., Snelgrove, A., \& Zajicek, J. M. (2009). The impact of community gardens on numbers of property crimes in urban Houston. HortTechnology, 19(2), 291-296.

8. Ikkai, Y., SHIMIZU, T., SATO, K., \& ming-shin, C. (1999). The psychological effect of public-private partitioning of space in the streets of residential area. JOURNAL OF ARCHITECTURE PLANNING AND ENVIRONMENTAL ENGINEERING, (526), 215-222.

9. Jennings, V., \& Bamkole, O. (2019). The Relationship between Social Cohesion and Urban Green Space: An Avenue for Health Promotion. International journal of environmental research and public health, 16(3), 452.

10. Jiang, B., Li, D., Larsen, L., \& Sullivan, W. C. (2016). A dose-response curve describing the relationship between urban tree cover density and self-reported stress recovery. Environment and Behavior, 48(4), 607629.

11. Julien, D., Richard, L., Gauvin, L., \& Kestens, Y. (2012). Neighborhood characteristics and depressive mood among older adults: an integrative review. International Psychogeriatrics, 24(8), 1207-1225.

12. Koga, K., \& Iwasaki, Y. (2013). Psychological and physiological effect in humans of touching plant foliage, using the semantic differential method and cerebral activity as indicators. Journal of physiological anthropology, 32(1), 7.

13. Kotozaki, Y. (2013). The psychological changes of horticultural therapy intervention for elderly women of earthquake-related areas. J. Trauma Treat., 2013b, 3(184), 2167-1222.

14. Kroenke, K., Spitzer, R. L., \& Williams, J. B. (2001). The PHQ-9: validity of a brief depression severity measure. Journal of general internal medicine, 16(9), 606-613.

15. L'Observatoire pour la Protection de l'Environnement et des Monuments Historiques de Tanger, FriedrichEbert-Stiftung foundation. 2016. Rapport annuel 2016. https://www.fes.org.ma/common /pdf/publications_pdf/OPEMHT_rapport/Rapport_annuel_historiques_Tanger_fr.pdf 
esteem, and depression among elderly urban residents: analysis of secondary survey data. International journal of environmental research and public health, 16(8), 1445.

17. Maas, J., Verheij, R. A., Groenewegen, P. P., De Vries, S., \& Spreeuwenberg, P. (2006). Green space, urbanity, and health: how strong is the relation?. Journal of Epidemiology \& Community Health, 60(7), 587-592.

18. Martinsen, E. W. (2009). Therapeutic horticulture in clinical depression: A prospective study. Research and Theory for Nursing Practice, 23(4), 312.

19. Masuda, Sadahiro, Hino, Usui.(2018). Physical environment of alleys for the promotion of potted plants. Volume 83 Issue 745 Pages 447-453

20. Moussaoui D (2007) Psychiatry and mental health in Morocco. Bull Acad Natl Méd 191(4-5):781-782

21. RGPH 2004 (2004). Recensement général de la population et de l'habitat de 2014. Caractéristiques démographiques et socio-économiques de la population. https://www.hcp.ma/downloads/RGPH2014_t17441.html

22. Soga, M., Gaston, K. J., \& Yamaura, Y. (2017). Gardening is beneficial for health: A meta-analysis. Preventive Medicine Reports, 5, 92-99.

23. TAKAHASHI, S., ITOH, H., \& SHIMOMURA, A. (2005). Relation of Plants' Arrangement Pattern and Spatial Character in an Alley of Densely Built-up Residential Areas of Tsukisima, Chuo-ward (PAPERS OF THE 23th SCIENTIFIC RESEARCH MEETING). Landscape Research Japan Online, 68(5), 879-882.

24. Ulrich, R. S., Simons, R. F., Losito, B. D., Fiorito, E., Miles, M. A., \& Zelson, M. (1991). Stress recovery during exposure to natural and urban environments. Journal of environmental psychology, 11(3), 201-230.

25. Waliczek, T. M., Mattson, R. H., \& Zajicek, J. M. (1996). Benefits of community gardening on quality-of-life issues. Journal of Environmental Horticulture, 14(4), 204-209.

26. Wardle, J., Steptoe, A., Guliš, G., Sartory, G., Sêk, H., Todorova, I., ... \& Ziarko, M. (2004). Depression, perceived control, and life satisfaction in university students from Central-Eastern and Western Europe. International journal of behavioral medicine, 11(1), 27-36.

27. Wolch, J. R., Byrne, J., \& Newell, J. P. (2014). Urban green space, public health, and environmental justice: The challenge of making cities 'just green enough'. Landscape and urban planning, 125, 234-244.

28. World Bank. 2012. Morocco - Promoting youth opportunities and participation (English). Washington, DC: World Bank. http://documents.worldbank.org/curated/en/507941468109463283/Morocco-Promotingyouth-opportunities-and-participation

29. Zhang, Y., Van den Berg, A., Van Dijk, T., \& Weitkamp, G. (2017). Quality over quantity: Contribution of urban green space to neighborhood satisfaction. International journal of environmental research and public health, 14(5), 535.

30. 水上象吾, \& 萩原清子. (2001). 緑に対する要求行動に基づいた緑量評価に関する一考察都市居住環 境における鉢植えの役割. 環境システム研究論文集, 29, 283-289.

31. 青木義次, \& 湯浅義晴. (1993). 開放的路地空間での領域化としてのあふれ出し: 路地空間へのあふれ 出し調査からみた計画概念の仮説と検証その 1. 日本建築学会計画系論文報告集, 449, 47-55. 